\title{
Timing of kidney biopsy in type 2 diabetic patients: a stepwise approach
}

\author{
Jyh-Tong Hsieh', Fu-Pang Chang ${ }^{2,3}$, An-Hang Yang ${ }^{2,3,4}$, Der-Cherng Tarng 3,4,5,6,7 and Chih-Yu Yang ${ }^{3,4,5,6,8^{*}}$
}

\begin{abstract}
Background: Diabetic nephropathy (DN) is the most prevalent cause of renal disease in type 2 diabetic patients and is usually diagnosed clinically. A kidney biopsy is considered when non-diabetic renal disease (NDRD) is suspected, such as rapid progression in renal function impairment and severe proteinuria. Still, there is yet no consensus on the timing of kidney biopsy in type 2 diabetic patients. This study aims to identify markers that can help differentiate between DN and NDRD and guide the decision of kidney biopsy.

Methods: We retrospectively reviewed patients with type 2 diabetes who received kidney biopsy from 2008 to 2017 at Taipei Veterans General Hospital. Ophthalmologist consultation and outpatient records, diagnosis of kidney biopsy, laboratory data, and clinical characteristics were collected.

Results: This study enrolled 160 type 2 diabetic patients, among which 120 (75\%) had isolated DN and 40 (25\%) had NDRD \pm DN (26 had isolated NDRD, and 14 had NDRD superimposed on DN). In multivariate logistic regression analysis, DM duration (odds ratio [OR]: 0.907; 95\% confidence interval [Cl]: 0.842-0.977; $P=0.01$ ), diabetic retinopathy (OR: 0.196; 95\% Cl: 0.061-0.627; $P=0.006)$, and urinary RBC (OR: 1.068; 95\% Cl: 1.024-1.115; $P=0.002$ ) were independent predictors of NDRD. In patients with diabetic retinopathy $(n=112,70 \%)$, the presence of proliferative diabetic retinopathy, pan-retinal photocoagulation, and hematuria were factors predicting NDRD; and in patients without diabetic retinopathy $(n=48,30 \%)$, short DM duration and hematuria were factors predicting NDRD.
\end{abstract}

Conclusions: Using diabetic retinopathy, DM duration, and hematuria, we developed a 3-step approach to stratify patients into three categories with the different likelihoods of having NDRD. Then different strategies could be taken accordingly. Our stepwise approach is easy to follow and may serve as an appropriate and useful tool to help clinicians in making decisions of kidney biopsy in type 2 DM patients presenting with kidney diseases.

Keywords: Diabetic nephropathy, Diabetic retinopathy, Hematuria, Kidney biopsy, Non-diabetic renal disease

\section{Background}

Type 2 diabetes mellitus (DM), with its increasing prevalence, is one of the most crucial health problems [1, 2], and diabetic nephropathy (DN) is the leading cause of kidney failure with replacement therapy worldwide $[3,4]$.

\footnotetext{
* Correspondence: cyyang3@vghtpe.gov.tw

${ }^{3}$ School of Medicine, National Yang-Ming University, Taipei, Taiwan ${ }^{4}$ Institute of Clinical Medicine, National Yang-Ming University, Taipei, Taiwan Full list of author information is available at the end of the article
}

DN is usually diagnosed clinically based on its typical presentations (i.e., a long-standing duration of diabetes, presence of diabetic retinopathy, albuminuria without hematuria, and gradually progressive loss of eGFR), and absence of clinical or laboratory evidence of other kidney diseases [5-7]. A kidney biopsy is not mandatory for diagnosing DN; otherwise, a biopsy should be considered when patients present with atypical features for $\mathrm{DN}$ and a non-diabetic renal disease (NDRD) is suspected.

Diabetes-independent factors can cause kidney injury even in patients with DM, resulting in different types of NDRD such as hypertensive nephrosclerosis, atheroembolic

(C) The Author(s). 2020 Open Access This article is licensed under a Creative Commons Attribution 4.0 International License, which permits use, sharing, adaptation, distribution and reproduction in any medium or format, as long as you give appropriate credit to the original author(s) and the source, provide a link to the Creative Commons licence, and indicate if changes were made. The images or other third party material in this article are included in the article's Creative Commons licence, unless indicated otherwise in a credit line to the material. If material is not included in the article's Creative Commons licence and your intended use is not permitted by statutory regulation or exceeds the permitted use, you will need to obtain permission directly from the copyright holder. To view a copy of this licence, visit http://creativecommons.org/licenses/by/4.0/. The Creative Commons Public Domain Dedication waiver (http://creativecommons.org/publicdomain/zero/1.0/) applies to the data made available in this article, unless otherwise stated in a credit line to the data. 
disease, genetic kidney disorders, glomerulonephritis, and all kinds of acute kidney injury [8, 9]. Treatment approaches for DN and NDRD may diverge. For instance, IgA nephropathy, focal segmental glomerulosclerosis, membranous glomerulonephritis, and other primary and secondary glomerular diseases usually benefit from personalized treatment with immunosuppressants, other than conservative treatment, such as glycemic control, blood pressure control, and lipid-lowering therapy [10]. Therefore, a kidney biopsy is crucial for NDRD in making an accurate diagnosis and planning appropriate treatment [3]. Compared with DN, patients with NDRD were reported to have a better prognosis in both overall survival and renal survival [11-13]. NDRD may have better outcomes when these conditions are identified early, and specific treatment are predisposed [10]. If clinicians do not suspect the presence of NDRD, a kidney biopsy will not be performed, and etiologies of NDRD will never be identified. As a consequence, patients with NDRD will be treated as $\mathrm{DN}$, and their outcomes will be jeopardized without proper therapy.

The prevalence of NDRD in DM patients varied widely between previous biopsy-based studies, ranging from 3 to $82.9 \%[10,14,15]$. Several factors may explain such high histological variability, including selection criteria, indications, and availability of kidney biopsy, as well as on the population investigated [16]. In particular, the criteria used to select patients with diabetes who would benefit from kidney biopsy were different among the studies. Only a small number of studies evaluated research-indicated biopsies, while the vast majority analyzed clinically indicated biopsies [10]. High variability in the prevalence of NDRD also indicated that there were patients who took unnecessary risks to receive a kidney biopsy with their pathology diagnosis turning out to be $\mathrm{DN}$. Besides, there is no formal practice guideline on when to arrange a kidney biopsy for patients with DM $[8,17]$.

In clinical practice, the value of kidney biopsy in DM patients is to identify NDRD, so proper treatment could be initiated in time. This study aims to explore factors that could help identify the presence of NDRD. We also attempt to propose a practical approach to guide the decision of kidney biopsy in patients with type $2 \mathrm{DM}$.

\section{Methods}

\section{Patients and data collection}

We retrospectively reviewed patients with type $2 \mathrm{DM}$ who received kidney biopsy at Taipei Veterans General Hospital, a tertiary-care referral center in Taiwan, between 2008 and 2017. Demographic and clinical data were collected from medical records, including age, gender, height, weight, body mass index (BMI), duration of DM before the biopsy, ophthalmic findings (including the presence of diabetic retinopathy, proliferative diabetic retinopathy $[\mathrm{PDR}]$ and macular edema $[\mathrm{ME}]$ ), and treatment received for diabetic retinopathy before biopsy (including focal photocoagulation [PC], pan-retinal photocoagulation [PRP], intravitreal injection [IVI], and vitrectomy $[\mathrm{VT}])$. We defined type $2 \mathrm{DM}$ according to diagnoses of inpatient and outpatient medical records. The duration of DM was also defined as accurately as possible according to the medical record. Laboratory data immediately before the biopsy was recorded, including serum creatinine, estimated glomerular filtration rate (eGFR, using the CKD-EPI formula [18]), level of HbA1c, urinary red blood cell $(\mathrm{RBC})$ and white blood cell (WBC) counts (presented as numbers of cells per high power field $[\mathrm{HPF}]$ ), and spot urine protein/creatinine ratio (UPCR). Kidney sizes were recorded according to the kidney ultrasonographic report.

\section{Kidney biopsy and pathology}

Indications of kidney biopsy were based on clinical features suggesting renal diseases other than $\mathrm{DN}$, including recent onset of heavy proteinuria or nephrotic syndrome, persistent hematuria with dysmorphic RBCs or $\mathrm{RBC}$ casts, and unexplained rapidly progressive renal failure. The decision on kidney biopsy was at the discretion of each attending nephrologist.

The kidney pathology of each patient was examined by two pathologists who were specialists in kidney diseases. The pathologic criteria for DN included diffuse mesangial expansion with the predominance of an increased mesangial matrix, Kimmelstiel-Wilson nodular lesions, hyaline exudative lesions, and glomerular basement membrane thickening. Based on pathological findings, patients were categorized as isolated DN or NDRD \pm DN (isolated NDRD or NDRD superimposed on DN).

\section{Statistical analysis}

Binary variables were expressed in counts and percentages. The chi-square test was used for comparisons of categorical variables. Continuous variables were described as mean \pm standard deviation for normally distributed data and as median (interquartile range [Q1, Q3]) for non-normally distributed data. Student's t-test or one-way analysis of variance (ANOVA) was used for normally distributed data analysis, and the MannWhitney $U$ test or Kruskal-Wallis test was used for skewed data analysis. Such variables associated with NDRD in univariate analysis with a significance less than 0.10 were retained for multivariate logistic regression analysis. Independent predictors of NDRD were identified by multivariate logistic regression analysis, with results reported as the odds ratio (OR) and 95\% confidence interval (CI). Receiver operating characteristic (ROC) curve analyses were performed to determine 
the best cut-off value of RBC count and duration of DM for predicting the presence of NDRD. All probabilities were two-tailed, and a $P$-value of less than 0.05 was considered to be statistically significant. Based on the status of the identified NDRD predictors, we divided patients into subgroups; patient distribution in subgroups by pathological diagnosis was examined. After subgroup analysis, we proposed a practical approach to guide kidney biopsy in type $2 \mathrm{DM}$ patients. Data were analyzed using Statistical Package for the Social Sciences (SPSS) for Windows, version 22.0 (IBM Corporation, Armonk, NY, USA).

\section{Results}

The number of patients with type 2 DM was 252 among the 567 patients who received kidney biopsy. We excluded 92 patients due to the following reasons: biopsy of graft kidney $(n=25)$, an inadequate specimen for pathology report $(n=1)$, lack of ophthalmology evaluation $(n=65)$, and unavailable urinalysis report $(n=1)$. A total of 160 patients was included in the analysis (Fig. 1). All of them received a kidney biopsy for the first time, and there were no known biopsy-proven kidney diseases. Prebiopsy demographics and characteristics are shown in Table 1. Screening for autoimmune diseases (including ANA, ANCA, cryoglobulin ...) was performed in some patients but not routinely performed before biopsy in every patient; we didn't include these examinations for analysis because of too much missing data.

Based on the result of kidney biopsy, 120 (75\%) patients had isolated DN, $40(25 \%)$ had NDRD \pm DN $(26$ had isolated NDRD, and 14 had NDRD superimposed on DN). Patients with isolated DN had a significantly longer duration of DM $(10[4,16]$ vs. $4[1,7.5]$ years, $P<0.001)$, and higher prevalence of diabetic retinopathy $(83.3 \%$ vs. $30 \%, P<0.001)$ than patients with NDRD \pm $\mathrm{DN}$. The urinary RBC count was significantly higher in patients with NDRD \pm DN than patients with DN (8 [4, $15.5]$ vs. $4[1.4,8] / \mathrm{HPF}, P<0.001)$. Patients with NDRD \pm DN also had significantly older age $(64.8 \pm 10.6$ vs. $54.8 \pm 11.7$ years, $P<0.001)$ and more male gender $(80 \%$ vs. $55.8 \%, P=0.006)$. There was no difference in UPCR, urine WBC count, HbA1c, eGFR, and kidney sizes between two groups (Table 1). Multivariate logistic regression analysis (included gender, age, DM duration, diabetic retinopathy, PDR, urinary $\mathrm{RBC}$, and right kidney size) disclosed that DM duration (odds ratio [OR]: 0.907; 95\% confidence interval $[\mathrm{CI}]: 0.842-0.977 ; P=0.01)$, diabetic retinopathy (OR: 0.196; 95\% CI: 0.061-0.627; $P=$ 0.006 ), and urinary RBC (OR: 1.068 ; 95\% CI: $1.024-$ $1.115 ; P=0.002)$ were independent predictors of NDRD (Table 2).

We divided all 160 patients into 4 groups according to presence of diabetic retinopathy and diagnosis of kidney pathology (presence of NDRD or not) (Fig. 2). In patients with diabetic retinopathy (Table 3 ), 100 had isolated DN (group 1) and 12 had NDRD $\pm \mathrm{DN}$ (group 2); the urinary $\mathrm{RBC}$ count was significantly higher in group 2 then group $1(8[4,43]$ vs. $4[4,8] / \mathrm{HPF}, P=0.004$; ROC cut-off value: $5.5 / \mathrm{HPF}, \mathrm{AUC}=0.743$ ) (Figure S1), and group1 had a significantly higher prevalence of PDR (56\% vs. $16.7 \%, P$

$=0.01)$ and PRP ( $54 \%$ vs. $16.7 \%, P=0.029)$. In patients without diabetic retinopathy (Table 4), 20 had isolated $\mathrm{DN}$ (group 3) and 28 had NDRD $\pm \mathrm{DN}$ (group 4); the urinary RBC count was significantly higher in group 4 than group $3(6[4,15.5]$ vs. $3.5[1,4] / \mathrm{HPF}, P<0.001$; ROC cut-off value: 6.0/HPF, AUC $=0.786$ ) (Figure S2), and group 3 had significantly longer duration of DM (10 $[3.5,19]$ vs. $2[1,7.5]$ years, $P=0.004$; ROC cut-off value: 4.5 years, $\mathrm{AUC}=0.745$ ) (Figure $\mathrm{S} 3$ ).

The patients were further divided into eight subgroups based on the presence of diabetic retinopathy, presence of PDR, and DM duration ( $\geq 5$ or $<5$ years) (Fig. 3 ), and

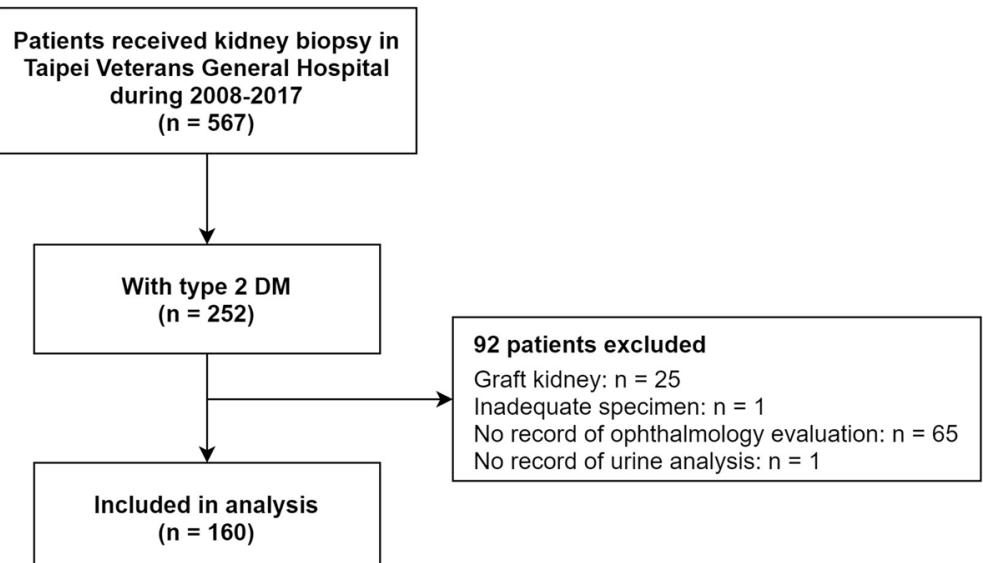

Fig. 1 Inclusion and exclusion of our study population 
Table 1 Clinical and biochemical characteristics of all patients included

\begin{tabular}{|c|c|c|c|}
\hline Characteristics & $\begin{array}{l}\text { Isolated DN } \\
n=120\end{array}$ & $\begin{array}{l}\text { NDRD } \pm \text { DN } \\
n=40\end{array}$ & $P$-value \\
\hline Gender (male) & $67(55.8 \%)$ & $32(80 \%)$ & 0.006 \\
\hline Age (year) & $54.8 \pm 11.7$ & $64.8 \pm 10.6$ & $<0.001$ \\
\hline Body weight (kg) & $67.3(58.7,75.4)$ & $71.8(63,75.6)$ & 0.246 \\
\hline Height (cm) & $163 \pm 8.5$ & $162.9 \pm 8.2$ & 0.919 \\
\hline $\mathrm{BMI}\left(\mathrm{kg} / \mathrm{m}^{2}\right)$ & $25.1(22.5,28.9)$ & $26.1(23.8,28.5)$ & 0.259 \\
\hline Duration of diabetes (yr) & $10(4,16)$ & $4(1,7.5)$ & $<0.001$ \\
\hline Diabetic retinopathy & $100(83.3 \%)$ & $12(30 \%)$ & $<0.001$ \\
\hline PDR & $56(46.7 \%)$ & $2(5 \%)$ & $<0.001$ \\
\hline ME & $15(12.5 \%)$ & $2(5 \%)$ & 0.244 \\
\hline PRP & $54(45 \%)$ & $2(5 \%)$ & $<0.001$ \\
\hline PC & $13(10.8 \%)$ & 0 & 0.039 \\
\hline $\mathrm{IVI}$ & $29(24.2 \%)$ & $1(2.5 \%)$ & 0.002 \\
\hline VT & $8(6.7 \%)$ & 0 & 0.202 \\
\hline $\mathrm{HbA1c}(\%)$ & $7.1(6.1,8.8)$ & $6.7(6,7.5)$ & 0.139 \\
\hline Serum creatinine $(\mathrm{mg} / \mathrm{dL})$ & $2.8(1.7,4.7)$ & $2.3(1.5,4.1)$ & 0.256 \\
\hline eGFR $\left(\mathrm{mL} / \mathrm{min} / 1.73 \mathrm{~m}^{2}\right)$ & $21.1(11.8,40)$ & $28.5(13.4,46)$ & 0.257 \\
\hline UPCR (1000 mg/g) & $9.1(5.7,12.3)$ & $7.6(3.2,14.8)$ & 0.546 \\
\hline Urinary red blood cells/HPF & $4(1.4,8)$ & $8(4,15.5)$ & $<0.001$ \\
\hline Urinary white blood cells/HPF & $1(1,4)$ & $1(1,4)$ & 0.307 \\
\hline Right kidney size $(\mathrm{cm})$ & $11.5 \pm 1.1$ & $11.1 \pm 1.3$ & 0.056 \\
\hline Left kidney size $(\mathrm{cm})$ & $11.5 \pm 1.2$ & $11.2 \pm 1.2$ & 0.214 \\
\hline
\end{tabular}

Values were presented as median (Q1, Q3), mean $\pm \mathrm{SD}$, or $\mathrm{n}(\%)$

$D N$ diabetic nephropathy, NDRD non-diabetic renal disease, $B M I$ body mass index, $P D R$ proliferative diabetic retinopathy, $M E$ macular edema, $P R P$ pan-retinal photocoagulation, $P C$ focal photocoagulation, $I V I$ intravitreal injection, VT vitrectomy, UPCR urine protein-to-creatinine ratio

subgroup analyses were conducted. In patients with PDR, there was no significant difference between patients with diabetic retinopathy and NDRD \pm DN (Table S1). In patients with non-proliferative diabetic retinopathy (NPDR), patients with NDRD $\pm \mathrm{DN}$ had significantly higher urinary $\mathrm{RBC}$ count $(8[4,43]$ vs. $4[4,8]$ /HPF, $P=0.024$ ) (Table S2). In patients without diabetic retinopathy and DM duration $\geq 5$ years, patients with $\mathrm{NDRD} \pm \mathrm{DN}$ had significantly higher urinary RBC count $(8[4,32.75]$ vs. $3[1,4] / \mathrm{HPF}, P<0.001)$ and older age at biopsy $(73.3 \pm 10.4$ vs. $62.4 \pm 11.0, P=0.025)$ (Table S3). In patients without diabetic retinopathy and DM duration $<5$ years, there was no significant difference between patients with diabetic retinopathy and NDRD \pm DN (Table S4). Patient distributions according to the presence of diabetic retinopathy, the presence of PDR, DM duration ( $\geq 5$ or $<5$ years), the presence of hematuria (urinary RBC count $>6 / \mathrm{HPF}$ ), and diagnoses of kidney pathology (isolated DN, NDRD + DN, or isolated NDRD) are shown as Figure S4.

According to the presence of NDRD predictors in the whole population and different subgroups, the patient distribution of this study is shown in Figure S4. Factors we used to divide patients into groups in different steps are listed as follows. Step 1, presence or absence of diabetic retinopathy. Step 2, presence or absence of PDR in patients with diabetic retinopathy and short $(<5$ years $)$ or long ( $\geq 5$ years) DM duration in patients without diabetic retinopathy. Step 3, presence (urinary $\mathrm{RBC} \geq 6 / \mathrm{HPF}$ ) and absence (urinary $\mathrm{RBC}<6 / \mathrm{HPF}$ ) of hematuria. By going through the above steps, we divided patients into eight subgroups, and patient numbers of different kidney pathology (isolated DN, NDRD + DN, and isolated NDRD) were listed for each subgroup. The prevalence of NDRD \pm DN differed between subgroups and increasing from the left side to the right side in Figure S4. Next, we classified patients into three categories, including low likelihood $(2 \sim 10 \%)$, intermediate likelihood $(17 \sim 28 \%)$, and high likelihood $(73 \sim 100 \%)$ of having an NDRD. Based on the above results, we proposed a 3-step approach to guide kidney biopsy in type 2 DM patients with kidney disease (Fig. 4). The three steps in Fig. 4 are similar to those in Figure S4. Step 3 in Fig. 4 was omitted in the two extreme groups (patients with PDR and patients without diabetic retinopathy \& having short DM duration) 
Table 2 Univariate and multivariate logistic regression analysis of significant predictors of NDRD

\begin{tabular}{|c|c|c|c|c|c|c|}
\hline \multirow[t]{2}{*}{ Factor } & \multicolumn{3}{|c|}{ Univariate } & \multicolumn{3}{|c|}{ Multivariate } \\
\hline & OR & $95 \% \mathrm{Cl}$ & $P$ value & OR & $95 \% \mathrm{Cl}$ & $P$ value \\
\hline Male gender & 3.164 & $1.346-7.436$ & $0.008^{\mathrm{a}}$ & 2.257 & $0.839-7.607$ & 0.099 \\
\hline Age (year) & 1.082 & $1.043-1.123$ & $<0.001^{\mathrm{a}}$ & 1.062 & $0.999-1.130$ & 0.055 \\
\hline Body weight (kg) & 1.003 & $0.978-1.029$ & 0.814 & & & \\
\hline Height (cm) & 0.998 & $0.955-1.042$ & 0.918 & & & \\
\hline BMI $\left(\mathrm{kg} / \mathrm{m}^{2}\right)$ & 1.016 & $0.938-1.102$ & 0.692 & & & \\
\hline Duration of diabetes (yr) & 0.906 & $0.854-0.961$ & $0.001^{\mathrm{a}}$ & 0.907 & $0.842-0.977$ & 0.01 \\
\hline Diabetic retinopathy & 0.086 & $0.037-0.196$ & $<0.001^{\mathrm{a}}$ & 0.196 & $0.061-0.627$ & 0.006 \\
\hline PDR & 0.055 & $0.013-0.238$ & $<0.001^{\mathrm{a}}$ & 0.181 & $0.024-1.371$ & 0.098 \\
\hline ME & 0.352 & $0.077-1.616$ & 0.179 & & & \\
\hline PRP & 0.058 & $0.013-0.251$ & $<0.001$ & & & \\
\hline PC & 0 & & 0.999 & & & \\
\hline IVI & 0.075 & $0.010-0.575$ & 0.013 & & & \\
\hline VT & 0 & & 0.999 & & & \\
\hline $\mathrm{HbA1c}(\%)$ & 0.849 & $0.698-1.032$ & 0.101 & & & \\
\hline Serum creatinine (mg/dL) & 0.985 & $0.859-1.130$ & 0.835 & & & \\
\hline $\mathrm{eGFR}\left(\mathrm{mL} / \mathrm{min} / 1.73 \mathrm{~m}^{2}\right)$ & 1.008 & $0.994-1.023$ & 0.265 & & & \\
\hline UPCR (1000 mg/g) & 1.005 & $0.948-1.066$ & 0.858 & & & \\
\hline Urinary red blood cells/HPF & 1.041 & $1.012-1.071$ & $0.005^{\mathrm{a}}$ & 1.068 & $1.024-1.115$ & 0.002 \\
\hline Urinary white blood cells/HPF & 0.998 & $0.982-1.014$ & 0.769 & & & \\
\hline Right kidney size (cm) & 0.723 & $0.517-1.012$ & $0.059^{a}$ & 1.033 & $0.611-1.747$ & 0.903 \\
\hline Left kidney size (cm) & 0.819 & $0.598-1.122$ & 0.214 & & & \\
\hline
\end{tabular}

$O R$ odds ratio, $C l$ confidence interval, NDRD non-diabetic renal disease, $B M I$ body mass index, $P D R$ proliferative diabetic retinopathy, $M E$ macular edema, $P R P$ panretinal photocoagulation, $P C$ focal photocoagulation, $I V I$ intravitreal injection, $V T$ vitrectomy, UPCR urine protein-to-creatinine ratio

${ }^{a}$ Variables further included in the multivariate logistic regression analysis

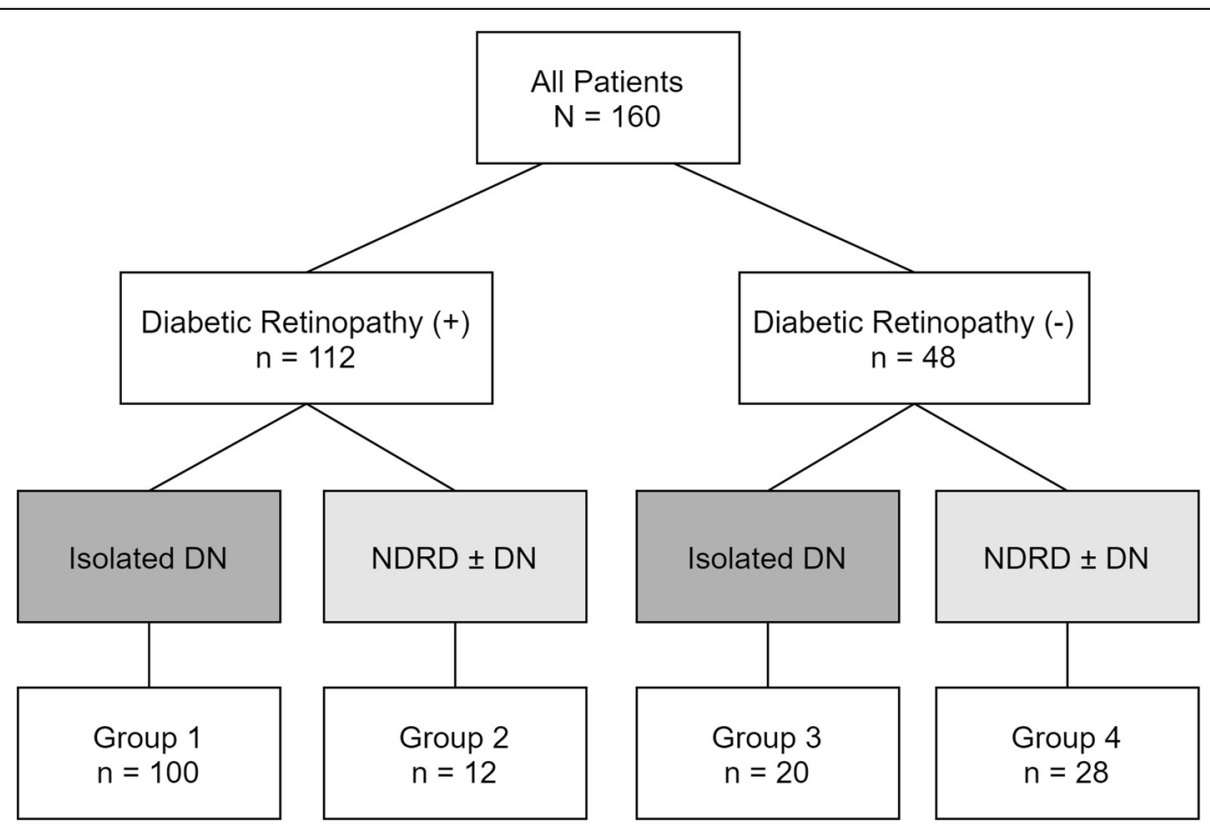

Fig. 2 Subgroup analyses in patients with and without diabetic retinopathy. DN, diabetic nephropathy; NDRD, non-diabetic renal disease 
Table 3 Clinical and biochemical characteristics of patients with diabetic retinopathy

\begin{tabular}{|c|c|c|c|}
\hline Characteristics & $\begin{array}{l}\text { Isolated DN } \\
\text { (Group 1) } \\
n=100\end{array}$ & $\begin{array}{l}\text { NDRD } \pm \text { DN } \\
\text { (Group 2) } \\
n=12\end{array}$ & $P$-value \\
\hline$\overline{\text { Gender (male) }}$ & $55(55 \%)$ & $10(83.3 \%)$ & 0.06 \\
\hline Age (year) & $55.3 \pm 11.5$ & $58.8 \pm 8.2$ & 0.111 \\
\hline Body weight (kg) & $67.3(56.3,77.4)$ & $71.8(67.4,74)$ & 0.451 \\
\hline Height $(\mathrm{cm})$ & $163.4 \pm 8.1$ & $165.3 \pm 8.8$ & 0.477 \\
\hline $\mathrm{BMI}\left(\mathrm{kg} / \mathrm{m}^{2}\right)$ & $24.4(22.2,28.4)$ & $25.5(24.2,28.3)$ & 0.623 \\
\hline Duration of diabetes (yr) & $10(4,15.8)$ & $6(3.5,7.5)$ & 0.217 \\
\hline \multicolumn{4}{|l|}{ Diabetic retinopathy } \\
\hline PDR & $56(56 \%)$ & $2(16.7 \%)$ & 0.01 \\
\hline ME & $15(15 \%)$ & $2(16.7 \%)$ & 1 \\
\hline PRP & $54(54 \%)$ & $2(16.7 \%)$ & 0.029 \\
\hline PC & $13(13 \%)$ & $0(0 \%)$ & 0.354 \\
\hline IVI & $29(29 \%)$ & $1(8.3 \%)$ & 0.176 \\
\hline VT & $8(8 \%)$ & $0(0 \%)$ & 0.596 \\
\hline $\mathrm{HbA1c}(\%)$ & $7.1(6.3,9.1)$ & $7.8(6.5,9.6)$ & 0.437 \\
\hline Serum creatinine $(\mathrm{mg} / \mathrm{dL})$ & $2.9(1.6,4.7)$ & $3.7(1.4,10.8)$ & 0.316 \\
\hline eGFR $\left(\mathrm{mL} / \mathrm{min} / 1.73 \mathrm{~m}^{2}\right)$ & $20.4(10.9,39.9)$ & $19.1(4.3,49.7)$ & 0.366 \\
\hline UPCR (1000 mg/g) & $9.1(6.2,12.5)$ & $7.2(3.1,11.9)$ & 0.214 \\
\hline Urinary red blood cells/HPF & $4(4,8)$ & $8(4,43)$ & 0.004 \\
\hline Urinary white blood cells/HPF & $1(1,4)$ & $1(1,4)$ & 0.69 \\
\hline Right kidney size $(\mathrm{cm})$ & $11.6 \pm 1.1$ & $11.7 \pm 1.2$ & 0.785 \\
\hline Left kidney size $(\mathrm{cm})$ & $11.5 \pm 1.2$ & $11.8 \pm 1.0$ & 0.481 \\
\hline
\end{tabular}

Values were presented as median (Q1, Q3), mean $\pm \mathrm{SD}$, or $\mathrm{n}(\%)$

$D N$ diabetic nephropathy, NDRD non-diabetic renal disease, $B M I$ body mass index, $P D R$ proliferative diabetic retinopathy, ME macular edema, $P R P$ panretinal photocoagulation, $P C$ focal photocoagulation, $I V I$ intravitreal injection, $V T$ vitrectomy, UPCR urine protein-to-creatinine ratio

Table 4 Clinical and biochemical characteristics of patients without diabetic retinopathy

\begin{tabular}{|c|c|c|c|}
\hline Characteristics & $\begin{array}{l}\text { Isolated DN } \\
\text { (Group 3) } \\
n=20 \\
\end{array}$ & $\begin{array}{l}\text { NDRD } \pm \text { DN } \\
(\text { Group } 4) \\
n=28\end{array}$ & $P$-value \\
\hline Gender (male) & $12(60 \%)$ & $22(78.6 \%)$ & 0.163 \\
\hline Age (year) & $62 \pm 10.1$ & $67.3 \pm 10.6$ & 0.087 \\
\hline Body weight (kg) & $69.6 \pm 11.5$ & $69.7 \pm 10.6$ & 0.962 \\
\hline Height (cm) & $161 \pm 10.3$ & $161.9 \pm 8$ & 0.742 \\
\hline $\mathrm{BMI}\left(\mathrm{kg} / \mathrm{m}^{2}\right)$ & $26.8 \pm 3.5$ & $26.5 \pm 3.1$ & 0.741 \\
\hline Duration of diabetes (yr) & $10(3.5,19)$ & $2(1,7.5)$ & 0.004 \\
\hline $\mathrm{HbA1c}(\%)$ & $6.9(5.7,8.6)$ & $6.5(5.9,7.2)$ & 0.391 \\
\hline Serum creatinine (mg/dL) & $2.4(1.7,3.4)$ & $2(1.5,3)$ & 0.305 \\
\hline $\operatorname{eGFR}\left(\mathrm{mL} / \mathrm{min} / 1.73 \mathrm{~m}^{2}\right)$ & $25.2(15.3,41.5)$ & $32.7(18.8,46)$ & 0.25 \\
\hline UPCR (1000 mg/g) & $7.7(4.4,12)$ & $10(3.4,16.1)$ & 0.605 \\
\hline Urinary red blood cells/HPF & $3.5(1,4)$ & $6(4,15.5)$ & $<0.001$ \\
\hline Urinary white blood cells/HPF & $1(1,4)$ & $1(1,4)$ & 0.522 \\
\hline Right kidney size (cm) & $10.9 \pm 0.9$ & $10.8 \pm 1.3$ & 0.854 \\
\hline Left kidney size (cm) & $11.3 \pm 1.1$ & $10.9 \pm 1.2$ & 0.291 \\
\hline
\end{tabular}

Values were presented as median $(\mathrm{Q} 1, \mathrm{Q} 3)$, mean $\pm \mathrm{SD}$, or $\mathrm{n}(\%)$ $D N$ diabetic nephropathy, NDRD non-diabetic renal disease, $B M I$ body mass index, UPCR urine protein-to-creatinine ratio because their subgroups were similar in terms of the prevalence of NDRD \pm DN.

The pathological diagnoses of NDRD identified in this study were listed in Table 5 . Within 40 patients with NDRD, the most common diagnoses of NDRD were membranous nephropathy $(14,35 \%)$, focal segmental glomerulosclerosis $(5,12.5 \%)$, and crescentic glomerulonephritis (5, 12.5\%). Membranous nephropathy (11, 42.3\%), focal segmental glomerulosclerosis (4, 15.4\%), and chronic tubulointerstitial nephritis $(3,11.5 \%)$ were the most common diagnoses in the 26 patients with isolated NDRD. Crescentic glomerulonephritis (4, 28.6\%), membranous nephropathy $(3,21.4 \%)$, and IgA nephropathy $(3,21.4 \%)$ were the most common diagnoses in the 14 patients with NDRD superimposed on DN. There was statistically more crescentic glomerulonephritis $(P=$ $0.024)$ and more $\operatorname{IgA}$ nephropathy $(P=0.014)$ in the NDRD + DN group than in the isolated NDRD group.

\section{Discussion}

Several pathological diagnoses had been identified in patients with NDRD. Membranous nephropathy and IgA nephropathy were the most common two pathological diagnoses in diabetic patients in the Asian population $[10,19-23]$. In our study population, $25 \%$ of patients 


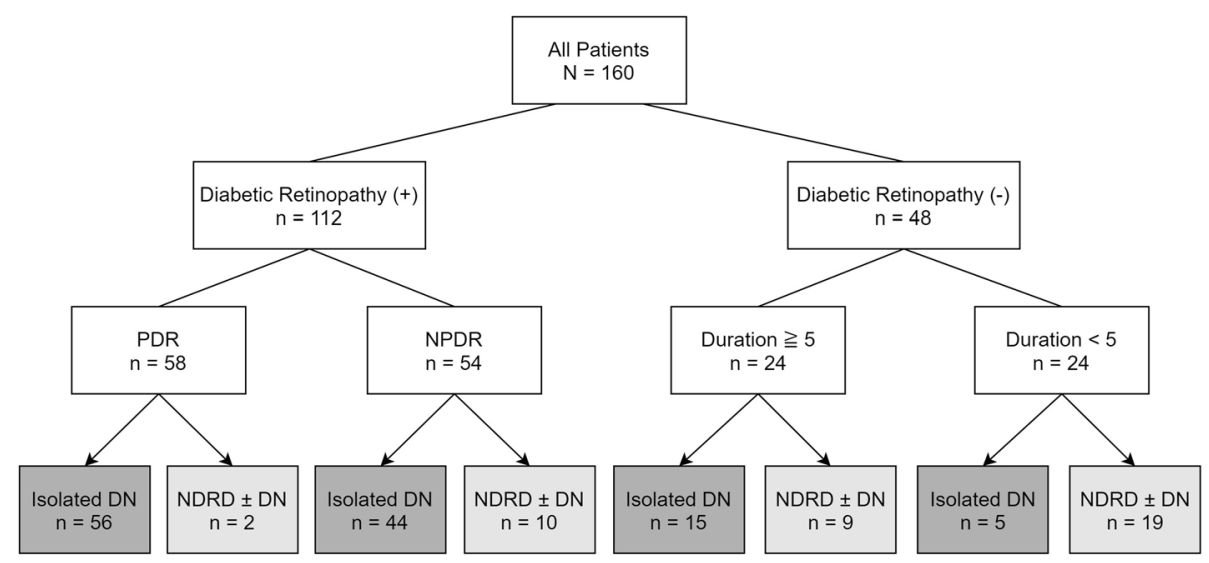

Fig. 3 Subgroup analyses: dividing patients according to diabetic retinopathy, proliferative diabetic retinopathy, and duration of diabetes. PDR, proliferative diabetic retinopathy; NPDR, non-proliferative diabetic retinopathy; DN, diabetic nephropathy; NDRD, non-diabetic renal disease

had NDRD (40 out of 160). Membranous nephropathy was the most common finding of NDRD (35\%), followed by focal segmental glomerulosclerosis (12.5\%), crescentic glomerulonephritis (12.5\%), IgA nephropathy (7.5\%), and chronic tubulointerstitial nephritis (7.5\%). The prevalence of IgA nephropathy was lower than previous reports. The distribution of pathological diagnoses is similar in patients with isolated NDRD, but the most common diagnosis in patients with NDRD superimposed on DN was crescentic glomerulonephritis (28.6\%) (Table 5).

We identified a few factors predicting the presence of NDRD, including the absence of diabetic retinopathy, short DM duration, and the presence of hematuria. The definition of hematuria varies in previous studies [16], and the cut-off value for DM duration was not consistent. The presence of diabetic retinopathy is clear-cut (yes or no), and in most circumstances, it is routinely

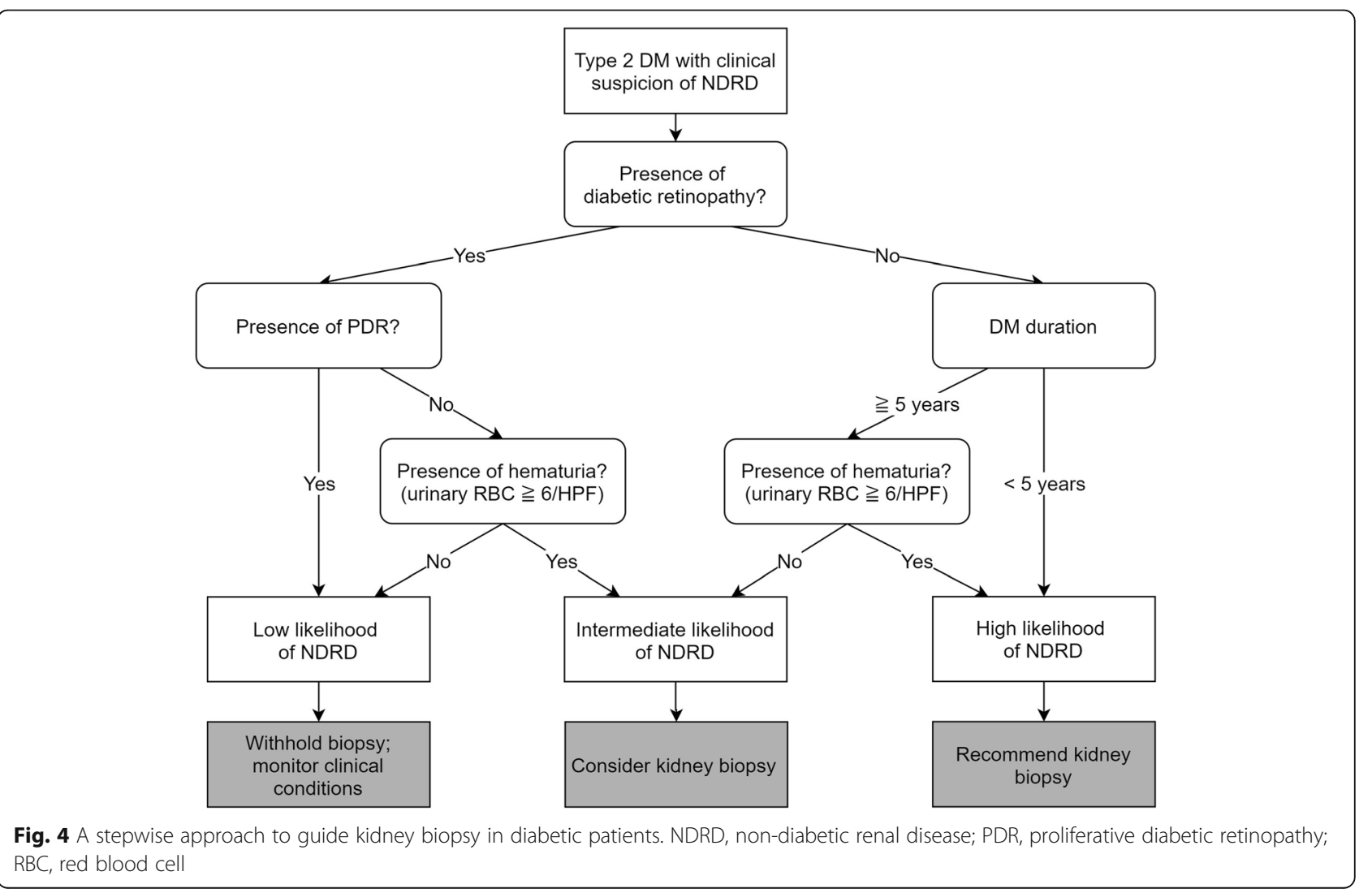


Table 5 Pathological diagnosis of NDRD

\begin{tabular}{|c|c|c|c|c|}
\hline Type of NDRD & $\begin{array}{l}\text { All } \\
(n=40)\end{array}$ & $\begin{array}{l}\text { Isolated NDRD } \\
(n=26)\end{array}$ & $\begin{array}{l}\text { NDRD + DN } \\
(n=14)\end{array}$ & $P$ value \\
\hline Membranous nephropathy & $14(35 \%)$ & $11(42.3 \%)$ & $3(21.4 \%)$ & 0.187 \\
\hline Focal segmental glomerulosclerosis & $5(12.5 \%)$ & $4(15.4 \%)$ & $1(7.1 \%)$ & 0.452 \\
\hline Crescentic glomerulonephritis & $5(12.5 \%)$ & $1(3.8 \%)$ & $4(28.6 \%)$ & 0.024 \\
\hline IgA nephropathy & $3(7.5 \%)$ & 0 & $3(21.4 \%)$ & 0.014 \\
\hline Chronic tubulointerstitial nephritis & $3(7.5 \%)$ & $3(11.5 \%)$ & 0 & 0.186 \\
\hline Minimal change disease & $2(5 \%)$ & $2(7.7 \%)$ & 0 & 0.287 \\
\hline Lupus nephritis & $2(5 \%)$ & $1(3.8 \%)$ & $1(7.1 \%)$ & 0.648 \\
\hline Amyloidosis & $1(2.5 \%)$ & $1(3.8 \%)$ & 0 & 0.457 \\
\hline Cryoglobulinemic glomerulonephritis & $1(2.5 \%)$ & $1(3.8 \%)$ & 0 & 0.457 \\
\hline Fibrillary glomerulonephritis & $1(2.5 \%)$ & 0 & $1(7.1 \%)$ & 0.168 \\
\hline Poststreptococcal glomerulonephritis & $1(2.5 \%)$ & 0 & $1(7.1 \%)$ & 0.168 \\
\hline Hypertensive nephropathy & $1(2.5 \%)$ & $1(3.8 \%)$ & 0 & 0.457 \\
\hline Acute interstitial nephritis & $1(2.5 \%)$ & $1(3.8 \%)$ & 0 & 0.457 \\
\hline
\end{tabular}

NDRD non-diabetic renal disease, $D N$ diabetic nephropathy

checked when DM patients were present with renal disease. That's why we chose diabetic retinopathy as the base of patient stratification. The close association between diabetic retinopathy and $\mathrm{DN}$ had been well analyzed. Ninety-five percent of patients with type $1 \mathrm{DM}$ and DN also have diabetic retinopathy [17], and diabetic retinopathy is also associated with preclinical histological damage in type $1 \mathrm{DM}$ patients [24]. In patients with type 2 DM, Tone et al. [23] demonstrated that diabetic retinopathy had the highest sensitivity (87\%) and specificity (93\%) in predicting the presence of DN. According to the KDOQI 2007 guidelines, the cause of CKD is attributable to DN in most people with diabetes if macroalbuminuria or microalbuminuria plus retinopathy is present [25]. However, diabetic retinopathy is concordant with $\mathrm{DN}$ in only about 60 to $65 \%$ of cases; its absence does not generate a high negative predictive value for the diagnosis of diabetic nephropathy [17]. Another study also suggested that diabetic retinopathy might be a poor predictor of $\mathrm{DN}$, in which $\mathrm{DN}$ was present in about $50 \%$ of diabetic patients without diabetic retinopathy. In comparison, up to $40 \%$ of patients with diabetic retinopathy had other renal diseases [26]. In our study, diabetic retinopathy was associated with isolated $\mathrm{DN}(P<0.001)$. In predicting NDRD $\pm \mathrm{DN}$, the absence of diabetic retinopathy had sensitivity and specificity as 70 and $83.3 \%$, respectively. All patients with diabetic retinopathy had DN, but $12(10.7 \%)$ of them also had NDRD $(\mathrm{NDRD}+\mathrm{DN})$. In patients without diabetic retinopathy, 22 (45.8\%) had DN, and 20 (41.7\%) of them had isolated DN in kidney pathology. Although there was a strong association between $\mathrm{DN}$ and diabetic retinopathy, the present study indicated that diabetic retinopathy alone had an imperfect predictive value [27]. In addition, the decision of biopsy cannot solely rely on the presence and absence of diabetic retinopathy.

We also examined factors reflecting the severity of diabetic retinopathy, including PDR, ME, and specific treatment received (such as PC, PRP, IVI, and VT). To our best knowledge, there were scarce studies analyzed these issues. A meta-analysis that examined four studies suggested that PDR may be a highly specific indicator for DN (pooled sensitivity $=25 \%$; pooled specificity $=98 \%$ ) [27]. In our study, the presence of PDR, PRP, PC, and IVI was associated with isolated DN (Table 1). In patients with diabetic retinopathy (group 1 vs. group 2; Fig. 2), significant differences were found on PDR and PRP between patients with isolated DN and NDRD \pm DN (Table 3). The absence of PDR and absence of PRP had similar sensitivity and specificity ( 83.3 and $56 \%$, versus 83.3 and $54 \%$ ) in predicting NDRD $\pm \mathrm{DN}$. We can find that the more severe the diabetic retinopathy was, the lower the likelihood of having NDRD. The presence and absence of PDR could provide additional clues on differentiating NDRD \pm DN from isolated $\mathrm{DN}$ in patients who had diabetic retinopathy.

Duration of DM is closely related to the prevalence of DN in type 1 patients. The prevalence rate of microalbuminuria and macroalbuminuria will increase after 10 years [25]. However, it's difficult to define the onset of type 2 DM accurately; therefore, the known duration is less strongly related to $\mathrm{DN}[17,25]$. Several studies still showed that DM duration was shorter in type $2 \mathrm{DM}$ patients with NDRD than patients with DN [19, 20, 28-32]. In our study, patients with NDRD $\pm \mathrm{DN}$ had a shorter duration of DM than patients with isolated DN (Table 1). In subgroup analyses, the difference could be found in patients without diabetic retinopathy (group 3 vs. group 4; 
Table 4) but not in patients with diabetic retinopathy (Table 3). The difference in DM duration might come from patients without diabetic retinopathy, and the duration of DM is also a factor predicting the presence of NDRD within this subgroup.

The presence of hematuria has been considered as one of the atypical features suggesting the presence of NDRD in the previous guidelines [25] and reports [16, 28, 30, 32-37]. However, there are also some studies suggesting that hematuria is not an uncommon finding in patients with typical DN (between 35 and 78\%) and thus is not useful in predicting NDRD [38-41]. Compared with NDRD, DN is characterized by a different pattern of glomerular lesions, which might result in a different type of hematuria. The most likely mechanism of hematuria in DN might be resulted from areas of aneurysmal dilatation in glomerular capillaries with subsequent rupture and pathological changes in the glomerular basement membrane [42]. Dysmorphic RBCs in the urine sediment may be more useful than microhematuria for indicating NDRD $[16,33]$. In our study, patients with NDRD $\pm \mathrm{DN}$ had significantly more urinary $\mathrm{RBC}$ than patients with isolated $\mathrm{DN}$ within all patients included and in most of the subgroup analyses. There was no significant difference in urinary RBC in only two subgroups; patients with PDR and patients without diabetic retinopathy and having short DM duration ( $<5$ years), in which the prevalence of NDRD was lowest and highest, respectively.

We further divided patients with NDRD into glomerulonephritis $(n=35)$ and other NDRD $(n=5)$, there were more urinary $\mathrm{RBC}$ in glomerulonephritis than that in isolated DN patients $(P=0.003)$. In addition, hematuria was not different between glomerulonephritis and other NDRD $(P=1.000)$, as well as other NDRD vs. isolated DN $(P=0.159)$ (Table S5). Our results supported the hypothesis that hematuria is an important factor in predicting the presence of NDRD, and it's also useful in different subgroups, including patients with diabetic retinopathy, patients with NPDR, patients without diabetic retinopathy, and patients without diabetic retinopathy \& having long DM duration.

It's still challenging to distinguish NDRD from patients with DM according to clinical presentation, and there is yet no consensus on detailed criteria to identify patients in whom kidney biopsy is mandatory. Previous studies have demonstrated several clinical manifestations which are predictive of the presence of NDRD, including the absence of diabetic retinopathy, short duration of DM, normal blood sugar, low level of HbA1c, presence of hematuria, heavy proteinuria, and low blood pressure $[9,10,16,19,20,27-35,37,42-51]$. However, the above NDRD predictors are actually DN-related, not NDRD-related. Therefore, it's more appropriate to use these factors in predicting $\mathrm{DN}$ rather than predicting
NDRD. Besides, the presence of NDRD and the presence of DN should be independent episodes; that is, even if one has factors suggesting a high likelihood of $\mathrm{DN}$, we cannot rule out the possibility of coexisting NDRD. Due to the above conditions, it's challenging to develop a widely accepted diagnostic tool to tell us which patient should receive kidney biopsy, and there is still no available guideline on this issue.

By using our 3-step approach, patients will be stratified into three categories by the likelihood of having NDRD. In patients with a high likelihood, we recommend performing a kidney biopsy to avoid missed diagnosis of NDRD. In patients with a low probability, a prompt kidney biopsy might increase the unnecessary risk of complications. Under such circumstances, a biopsy could be re-evaluated after a period of time. As for patients with an intermediate likelihood, the decision of biopsy should be judged by the clinical context and experience of each clinician. If a patient doesn't receive kidney biopsy initially, re-evaluation is indicated either periodically or when clinical condition changes (e.g., increasing urinary RBC count). A kidney biopsy will be suggested once the patient becomes classified into a high likelihood of NDRD in repeated evaluation. Previous studies have identified various predictors of NDRD [19]; correlations with each predictor were presented, but they are not applicable in daily practice. Our stepwise approach provides an easy way to define patients as the different likelihood of having NDRD, and clinicians could take different strategies accordingly. The decision on kidney biopsy or not can be more difficult in some specific scenarios, such as patients with relative contraindications for kidney biopsy. Our stepwise approach can be particularly useful in such conditions and help to make the decision making of kidney biopsy more accurate.

Our study has some limitations. Firstly, this is a biopsy-based study. Kidney biopsies were performed for diagnostic purposes but not for research purposes, and selection bias must exist. All the patients included had been selected by clinicians before biopsy and could not represent the true population of patients with type 2 $\mathrm{DM}$ and kidney disease. Besides, the indications of kidney biopsy were not standardized in this retrospective study. Patients presented with typical findings of DN would not receive a biopsy and were therefore excluded from our study. As a single-center study in Taiwan, the results can only be applied in the Asian population. This is a retrospective study with limited population size, and baseline characteristics such as age and gender were not similar between isolated DN group and NDRD \pm DN group. For the evaluation of hematuria, the data of dysmorphic RBCs was not available in every patient, so we could not assess the diagnostic value of glomerular hematuria. Our analyses only included data at the time 
of biopsy. Previous data of renal function, proteinuria, and hematuria were not available, which precluded us from analyzing these variables. Without baseline renal function, we didn't know whether a patient had acute kidney injury, which is one of the crucial indications of kidney biopsy. The optimal approach for patients with acute kidney injury might be different from other DM patients. Our 3-step approach stratifies patients into 3 categories with varying likelihoods of having NDRD, and there is no standard measure and no standard definition on such risk stratification. Besides, this is a descriptive study that can help hypothesis generation but not to address causal relationships. Further prospective research is warranted to validate this approach.

\section{Conclusions}

In conclusion, a kidney biopsy is essential for diabetic patients to diagnose NDRD accurately, and outcomes will be improved in NDRD patients once timely treatment is applied. However, loose criteria for performing kidney biopsy will yield unnecessary risks of bleeding complications, especially in patients under high risks, such as having high blood pressure and bleeding diathesis. Even though several clinical factors had been identified as predictors of NDRD, but we still don't know precisely who should receive a kidney and who should not, and there is no detailed consensus or guideline on this issue. We proposed a 3-step approach to stratify diabetic patients into three categories with different likelihoods of NDRD, by using the presence of diabetic retinopathy, DM duration, and hematuria. Our stepwise approach is easy to follow and may serve as a useful tool to help clinicians in making decisions of kidney biopsy in type $2 \mathrm{DM}$ patients presenting with kidney diseases.

\section{Supplementary information}

Supplementary information accompanies this paper at https://doi.org/10. 1186/s12882-020-01794-w.

Additional file 1: Figure S1. The receiver operating characteristic (ROC) curve of urinary RBC predicting NDRD in patients with diabetic retinopathy. The ROC area under the curve $(A \cup C)=0.743$

Additional file 2: Figure S2. The receiver operating characteristic (ROC) curve of urinary RBC predicting NDRD in patients without diabetic retinopathy. The $R O C$ area under the curve $(A \cup C)=0.786$.

Additional file 3: Figure S3. The receiver operating characteristic (ROC) curve of duration of diabetes predicting NDRD in patients without diabetic retinopathy. The $\mathrm{ROC}$ area under the curve $(A \cup C)=0.745$.

Additional file 4: Figure S4. Patient distribution according to diabetic retinopathy, proliferative diabetic retinopathy, DM duration $(\geq 5$ or $<5$ years), hematuria (urine RBC count $>6 / \mathrm{HPF}$ ), and diagnosis of kidney pathology. The prevalence of the non-diabetic renal disease in each subgroup is presented at the bottom. PDR, proliferative diabetic retinopathy; NPDR, non-proliferative diabetic retinopathy; DN, diabetic nephropathy; NDRD, non-diabetic renal disease.

Additional file 5: Table S1. Clinical and biochemical characteristics of patients with proliferative diabetic retinopathy. Table S2. Clinical and biochemical characteristics of patients with non-proliferative diabetic retinopathy. Table S3. Clinical and biochemical characteristics of patients without diabetic retinopathy \& with DM duration $\geq 5$ years. Table S4.

Clinical and biochemical characteristics of patients without diabetic retinopathy \& with DM duration < 5 years Table S5. Urinary red blood cells in different pathological diagnosis.

\section{Abbreviations}

ANOVA: Analysis of variance; BMl: Body mass index; Cl: Confidence interval; DM: Diabetes mellitus; DN: Diabetic nephropathy; IVI: Intravitreal injection; ME: Macular edema; NDRD: Non-diabetic renal disease; PC: Focal photocoagulation; PRP: Pan-retinal photocoagulation; PDR: Proliferative diabetic retinopathy; RBC: Red blood cell; ROC: Receiver operating characteristic; SPSS: Statistical Package for the Social Sciences; UPCR: Spot urine protein/creatinine ratio; VT: Vitrectomy; WBC: White blood cell

\section{Acknowledgements}

Not applicable.

\section{Authors' contributions}

$J H, F C, A Y, D T$, and CY contributed to the study conception and design. Material preparation, data collection, and analysis were performed by $\mathrm{JH}, \mathrm{FC}$, $A Y$, and $C Y$. The first draft of the manuscript was written by $\mathrm{JH}$ and FC. AY, $D T$, and $C Y$ commented on previous versions of the manuscript. JH, FC, AY, DT, and CY read and approved the final manuscript.

\section{Funding}

This work was supported financially for research purpose by the "Yin YenLiang Foundation Development and Construction Plan" of the School of Medicine, National Yang-Ming University, Taipei, Taiwan (107F-M01-0504), the Ministry of Science and Technology, Taipei, Taiwan (MOST 105-2628-B075-008-MY3 and MOST 108-2633-B-009-001), and a grant from Taipei Veterans General Hospital, Taipei, Taiwan (V106D25-003-MY3 and VGHUST107-G5-3-3). Also, this work was in part supported financially for research purposes by the "Center for Intelligent Drug Systems and Smart Biodevices $\left(\right.$ IDS $\left.^{2} \mathrm{~B}\right)$ " from The Featured Areas Research Center Program within the framework of the Higher Education Sprout Project by the Ministry of Education (MOE) in Taiwan. The funders have no role in study design, data collection, analysis, and interpretation, or in writing of the manuscript.

\section{Availability of data and materials}

The datasets used and analyzed during the current study are available from the corresponding author on reasonable request.

\section{Ethics approval and consent to participate}

This research was conducted ethically in accordance with the ethical standards of the Institutional Review Board of Taipei Veterans General Hospital (reference number: 2018-06-011AC) and with the World Medical Association Declaration of Helsinki and its later amendments or comparable ethical standards.

\section{Consent for publication}

Not applicable.

\section{Competing interests}

The authors declare that they have no competing interests.

\section{Author details}

'Division of Nephrology, Department of Medicine, Chiayi Branch, Taichung Veterans General Hospital, Chiayi, Taiwan. ${ }^{2}$ Department of Pathology, Taipei Veterans General Hospital, Taipei, Taiwan. ${ }^{3}$ School of Medicine, National Yang-Ming University, Taipei, Taiwan. ${ }^{4}$ Institute of Clinical Medicine, National Yang-Ming University, Taipei, Taiwan. ${ }^{5}$ Division of Nephrology, Department of Medicine, Taipei Veterans General Hospital, Taipei, Taiwan. ${ }^{6}$ Center for Intelligent Drug Systems and Smart Bio-devices (IDS2B), Hsinchu, Taiwan. ${ }^{7}$ Department and Institute of Physiology, National Yang-Ming University, Taipei, Taiwan. ${ }^{8}$ Stem Cell Research Center, National Yang-Ming University, Taipei, Taiwan. 
Received: 20 January 2020 Accepted: 5 April 2020

\section{Published online: 15 April 2020}

\section{References}

1. Zimmet PZ, Magliano DJ, Herman WH, Shaw JE. Diabetes: a 21st century challenge. Lancet Diabetes Endocrinol. 2014;2(1):56-64.

2. Guariguata L, Whiting DR, Hambleton I, Beagley J, Linnenkamp U, Shaw JE. Global estimates of diabetes prevalence for 2013 and projections for 2035. Diabetes Res Clin Pract. 2014;103(2):137-49.

3. Prakash J. Non-diabetic renal disease (NDRD) in patients with type 2 diabetes mellitus (type 2 DM). J Assoc Physicians India. 2013;61(3):194-9.

4. Levey AS, Eckardt K-U, Dorman NM, Christiansen SL, Hoorn EJ, Ingelfinger $J R$, et al. Nomenclature for kidney function and disease: report of a kidney disease: improving global outcomes (KDIGO) consensus conference. Kidney Int. 2020. https://doi.org/10.1016/J.KINT.2020.02.010.

5. American Diabetes Association. Microvascular complications and foot care: standards of medical care in diabetes-2019. Diabetes Care. 2019; 42(Supplement 1): S124-S138.

6. Foundation NK. KDOQI clinical practice guideline for diabetes and CKD: 2012 update. Am J Kidney Dis. 2012;60(5):850-86.

7. Parving HH, Gall MA, Skøtt P, Jørgensen HE, Løkkegaard H, Jørgensen F, et al. Prevalence and causes of albuminuria in non-insulin-dependent diabetic patients. Kidney Int. 1992;41:758-62.

8. Anders $\mathrm{H}-\mathrm{J}$, Huber TB, Isermann B, Schiffer M. CKD in diabetes: diabetic kidney disease versus nondiabetic kidney disease. Nat Rev Nephrol. 2018;14: 361-77.

9. Sharma SG, Bomback AS, Radhakrishnan J, Herlitz LC, Stokes MB, Markowitz GS, et al. The modern spectrum of renal biopsy findings in patients with diabetes. Clin J Am Soc Nephrol. 2013;8:1718-24.

10. Fiorentino M, Bolignano D, Tesar V, Pisano A, Van Biesen W, Tripepi G, et al. Renal biopsy in patients with diabetes: a pooled meta-analysis of 48 studies. Nephrol Dial Transplant. 2017;32:97-110.

11. Iwai T, Miyazaki M, Yamada G, Nakayama M, Yamamoto T, Satoh M, et al. Diabetes mellitus as a cause or comorbidity of chronic kidney disease and its outcomes: the Gonryo study. Clin Exp Nephrol. 2018;22:328-36.

12. Tan J, Zwi LJ, Collins JF, Marshall MR, Cundy T. Presentation, pathology and prognosis of renal disease in type 2 diabetes. BMJ Open Diabetes Res Care. 2017:5:1-9.

13. Lee YH, Kim KP, Kim YG, Moon JY, Jung SW, Park E, et al. Clinicopathological features of diabetic and nondiabetic renal diseases in type 2 diabetic patients with nephrotic-range proteinuria. Medicine (Baltimore). 2017;96:1-7.

14. Zhuo L, Ren W, Li W, Zou G, Lu J. Evaluation of renal biopsies in type 2 diabetic patients with kidney disease: a clinicopathological study of 216 cases. Int Urol Nephrol. 2013;45(1):173-9.

15. Olsen S, Mogensen CE. How often is NIDDM complicated with non-diabetic renal disease? An analysis of renal biopsies and the literature. Diabetologia. 1996;39(12):1638-45

16. Jiang S, Wang Y, Zhang Z, Dai P, Yang Y, Li W. Accuracy of hematuria for predicting non-diabetic renal disease in patients with diabetes and kidney disease: a systematic review and meta-analysis. Diabetes Res Clin Pract. 2018;143:288-300.

17. Umanath K, Lewis JB. Update on diabetic nephropathy: core curriculum 2018. Am J Kidney Dis. 2018;71:884-95.

18. Levey AS, Stevens LA, Schmid CH, Zhang YL, Castro AF, Feldman Hl, et al. A new equation to estimate glomerular filtration rate. Ann Intern Med. 2009; 150:604-12.

19. Liu D, Huang T, Chen N, Xu G, Zhang P, Luo Y, et al. The modern spectrum of biopsy-proven renal disease in Chinese diabetic patients-a retrospective descriptive study. PeerJ. 2018;6:e4522.

20. Liu S, Guo Q, Han H, Cui P, Liu X, Miao L, et al. Clinicopathological characteristics of non-diabetic renal disease in patients with type 2 diabetes mellitus in a northeastern Chinese medical center: a retrospective analysis of 273 cases. Int Urol Nephrol. 2016;48:1691-8.

21. Byun JM, Lee CH, Lee SR, Moon JY, Lee SH, Lee TW, et al. Renal outcomes and clinical course of nondiabetic renal diseases in patients with type 2 diabetes. Korean J Intern Med. 2013;28:565-72.

22. Oh SW, Kim S, Na KY, Chae DW, Kim S, Jin DC, et al. Clinical implications of pathologic diagnosis and classification for diabetic nephropathy. Diabetes Res Clin Pract. 2012;97:418-24.
23. Tone A, Shikata K, Matsuda M, Usui H, Okada S, Ogawa D, et al. Clinical features of non-diabetic renal diseases in patients with type 2 diabetes. Diabetes Res Clin Pract. 2005;69:237-42.

24. Klein R, Zinman B, Gardiner R, Suissa S, Donnelly SM, Sinaiko AR, et al. The relationship of diabetic retinopathy to preclinical diabetic glomerulopathy lesions in type 1 diabetic patients: the renin-angiotensin system study. Diabetes. 2005;54(2):527-33.

25. KDOQI. KDOQI clinical practice guidelines and clinical practice recommendations for diabetes and chronic kidney disease. Am J Kidney Dis. 2007;49(2 Suppl 2):S12-154.

26. Prakash J, Lodha M, Singh SK, Vohra R, Raja R, Usha. Diabetic retinopathy is a poor predictor of type of nephropathy in proteinuric type 2 diabetic patients. J Assoc Physicians India. 2007;55(JUNE):412-6.

27. He F, Xia X, Wu XF, Yu XQ, Huang FX. Diabetic retinopathy in predicting diabetic nephropathy in patients with type 2 diabetes and renal disease: a meta-analysis. Diabetologia. 2013;56:457-66

28. Kritmetapak K, Anutrakulchai S, Pongchaiyakul C, Puapairoj A. Clinical and pathological characteristics of non-diabetic renal disease in type 2 diabetes patients. Clin Kidney J. 2018;11:342-7.

29. Dong Z, Wang Y, Qiu Q, Zhang X, Zhang L, Wu J, et al. Clinical predictors differentiating non-diabetic renal diseases from diabetic nephropathy in a large population of type 2 diabetes patients. Diabetes Res Clin Pract. 2016; 121:112-8.

30. Liu M, Chen X, Sun X, Zhou J, Zhang X, Zhu H, et al. Validation of a differential diagnostic model of diabetic nephropathy and non-diabetic renal diseases and the establishment of a new diagnostic model. J Diabetes. 2014;6:519-26.

31. Liang S, Zhang XG, Cai GY, Zhu HY, Zhou JH, Wu J, et al. Identifying parameters to distinguish non-diabetic renal diseases from diabetic nephropathy in patients with type 2 diabetes mellitus: a meta-analysis. PLoS One. 2013;8:e64184

32. Chong YB, Keng TC, Tan LP, Ng KP, Kong WY, Wong CM, et al. Clinical predictors of non-diabetic renal disease and role of renal biopsy in diabetic patients with renal involvement: a single Centre review. Ren Fail. 2012;34: 323-8.

33. Dong ZY, Wang YD, Qiu Q, Hou K, Zhang L, Wu J, et al. Dysmorphic erythrocytes are superior to hematuria for indicating non-diabetic renal disease in type 2 diabetics. J Diabetes Investig. 2016;7:115-20.

34. Bi H, Chen N, Ling G, Yuan S, Huang G, Liu R. Nondiabetic renal disease in type 2 diabetic patients: a review of our experience in 220 cases. Ren Fail. 2011;33:26-30

35. Zhou J, Chen X, Xie Y, Li J, Yamanaka N, Tong X. A differential diagnostic model of diabetic nephropathy and non-diabetic renal diseases. Nephrol Dial Transplant. 2008;23:1940-5.

36. Akimoto T, Ito C, Saito O, Takahashi H, Takeda S, Ando Y, et al. Microscopic hematuria and diabetic glomerulosclerosis - Clinicopathological analysis of type 2 diabetic patients associated with overt proteinuria. Nephron Clin Pract. 2008;109:119-26.

37. Mak SK, Gwi E, Chan KW, Wong PN, Lo KY, Lee KF, et al. Clinical predictors of non-diabetic renal disease in patients with non-insulin dependent diabetes mellitus. Nephrol Dial Transplant. 1997:12:2588-91.

38. O'Neill WM, Wallin JD, Walker PD. Hematuria and red cell casts in typical diabetic nephropathy. Am J Med. 1983;74(3):389-95.

39. Amoah E, Glickman JL, Malchoff CD, Sturgill BC, Kaiser DL, Bolton WK. Clinical identification of nondiabetic renal disease in diabetic patients with type I and type II disease presenting with renal dysfunction. Am J Nephrol. 1988;8(3):204-11.

40. Lopes De Faria JBML, Lopes De Faria SR, Ramos OL, Pereira AB. Glomerular hematuria in diabetics. Clin Nephrol. 1988;30:117-21.

41. Serra A, Romero R, Bayés B, Lopez D, Bonet J. Is there a need for changes in renal biopsy criteria in proteinuria in type 2 diabetes? Diabetes Res Clin Pract. 2002:58(2):149-53.

42. Hayashi H, Karasawa R, Inn H, Saitou T, Ueno M, Nishi S, et al. An electron microscopic study of glomeruli in Japanese patients with non-insulin dependent diabetes mellitus. Kidney Int. 1992;41(4):749-57.

43. Fan JZ, Wang R. Non-diabetic renal disease in patients with type 2 diabetes: a single Centre study. Intern Med J. 2018;48:451-6.

44. Yenigun EC, Dede F, Ozturk R, Turgut D, Koc E, Piskinpasa SV, et al. Nondiabetic renal disease in diabetes mellitus: clinical features and renal biopsy findings. Hippokratia. 2015;19:148-52. 
45. Soleymanian T, Hamid G, Arefi M, Najafi I, Ganji MR, Amini M, et al. Nondiabetic renal disease with or without diabetic nephropathy in type 2 diabetes: clinical predictors and outcome. Ren Fail. 2015;37:572-5.

46. Sabanayagam C, Foo VHX, Ikram MK, Huang H, Lim SC, Lamoureux EL, et al. Is chronic kidney disease associated with diabetic retinopathy in Asian adults? J Diabetes. 2014;6:556-63.

47. Wilfred DC, Mysorekar W, Venkataramana RS, Eshwarappa M, Subramanyan R. Nondiabetic renal disease in type 2 diabetes mellitus patients: a clinicopathological study. J Lab Physicians. 2013;5:94-9.

48. Harada K, Akai Y, Sumida K, Yoshikawa M, Takahashi H, Yamaguchi Y, et al. Significance of renal biopsy in patients with presumed diabetic nephropathy. J Diabetes Investig. 2013;4:88-93.

49. Mou S, Wang Q, Liu J, Che X, Zhang M, Cao L, et al. Prevalence of nondiabetic renal disease in patients with type 2 diabetes. Diabetes Res Clin Pract. 2010;87:354-9.

50. Wu WP, Shu KH, Cheng CH, Chen CH, Lee WC. Proteinuria over $7 \mathrm{G}$ per day predicts non-diabetic nephropathy in type 2 diabetic patients. Acta Nephrologica. 2006;20:22-7.

51. Soni SS, Gowrishankar S, Kishan AG, Raman A. Non diabetic renal disease in type 2 diabetes mellitus. Nephrology. 2006;11:533-7.

\section{Publisher's Note}

Springer Nature remains neutral with regard to jurisdictional claims in published maps and institutional affiliations.

Ready to submit your research? Choose BMC and benefit from:

- fast, convenient online submission

- thorough peer review by experienced researchers in your field

- rapid publication on acceptance

- support for research data, including large and complex data types

- gold Open Access which fosters wider collaboration and increased citations

- maximum visibility for your research: over $100 \mathrm{M}$ website views per year

At $\mathrm{BMC}$, research is always in progress.

Learn more biomedcentral.com/submissions 